\title{
The effect of particles integrity on the damping capacities of fly-ash cenospheres/AZ91D composites
}

\author{
Fan-GuoLi $i^{1, a}$, Si-RongYu ${ }^{1, b}$, Yuan-Ming ${ }^{1, c}$ \\ ${ }^{1}$ College of Mechanical and Electronic Engineering, China University of Petroleum, Qingdao \\ 266580, China \\ aemail: leego113@126.com bemail: simon4179@163.com cemail:yuanmingp@163.com \\ Funds: The Key Grant Project of Chinese Ministry of China Education (No:313056) and \\ Fundamental Research Funds for the China Central Universities(14CX02132A)
}

Keywords: Metallic composites; Fly ash cenospheres; Microstructure; Damping capacity; Particle integrity

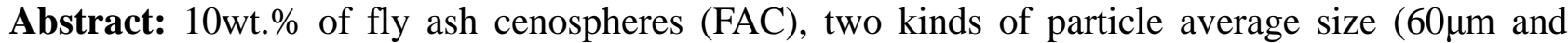
$120 \mu \mathrm{m}$ ), two kinds of particles morphology (ball-milled to powder fragments and non-ball milled), were added to the AZ91D Mg alloy slurry to prepare the four kinds of magnesium matrix composites by stirring casting method. The effect of the particles integrity and particles size of FAC on the phases, microstructure and damping capacities of the composites was investigated. The XRD patterns and microstructure show that the new phases were produced. The damping measurement results illustrate that with the particles size increasing, the damping capacities of the composites increase, and ball-milled FAC particles have more effective on the damping capacities than that of non-ball milled particles at both $20^{\circ} \mathrm{C}$ and elevated to $320^{\circ} \mathrm{C}$. moreover, the particles morphology has a greater $15 \%$ impact on damping capacities than the particles size at room temperature and $8 \%$ at elevated temperature.
\end{abstract}

\section{Introduction}

Magnesium alloys, the lightest commercial alloys, have great potential for high performance aerospace and automotive applications [1,2]. The Mg alloys especially AZ series which have high specific strength, high specific stiffness and excellent shock absorption properties.However, magnesium alloys have poor corrosion resistance, poor wear resistance, poor creep resistanceand low yield strength.Magnesium matrix composites (MMCs) have higher specific stiffness and specific strength, better wear resistance and high mechanical and damping capacity.

The ultra light fly ash cenosphere (FAC), containing about $62.79 \% \mathrm{SiO}_{2}, \quad 24.24 \% \mathrm{Al}_{2} \mathrm{O}_{3}$, $3.86 \% \mathrm{Fe}_{2} \mathrm{O}_{3}, 1.78 \% \mathrm{CaO}, 1.28 \% \mathrm{MgO}$ and others, one of the by-product during the combustion of coal in thermal power plants. Adding the FAC to the magnesium alloys slurry, there would generate $\mathrm{Mg}_{2} \mathrm{Si}$ by the reaction between $\mathrm{SiO}_{2}$ in the FAC and $\mathrm{Mg}$, which is expected to improve the damping capacities of magnesium alloys[3,4]. $\mathrm{Mg}_{2} \mathrm{Si}$ intermetallic compound in magnesium alloy, which also guarantees free movement of dislocaiton segments [5].After ball-milled about 16h, the FAC turned from the cenospheres to the powder fragments. As increasing the contact area with the Mg alloy, the reaction between them is more abundent.

\section{Experimental}

\subsection{Preparation of magnesium matrix composites}

The magnesium matrix composites were prepared by the stirring casting method. AZ91D alloy were melt in an electric resistance furnace under the protection of mixture of 3vol.\% SF6 and 97vol.\%CO2. 10wt.\% FAC particles were added as the temperature of Mg alloy slurry rises to 590(C stirring at the rotation speed of $700 \mathrm{rpm}$ for $1 \mathrm{~min}$. So, the four kinds of reinforcemets preparing the $\mathrm{Mg}$ matrix composites were obtained, S1(average size $120 \mu \mathrm{m}$ ball milled), S2(average size $120 \mu \mathrm{m}$ non-ball milled), S3(average size $60 \mu \mathrm{m}$ ball milled)and S4(average size 
$60 \mu \mathrm{m}$ non-ball milled) respectively. Fig.1 shows the SEM graph of non-ball milled (Fig.1a) and ball-milled (Fig.1b) fly-ash cenospheres (FAC) under respectively.

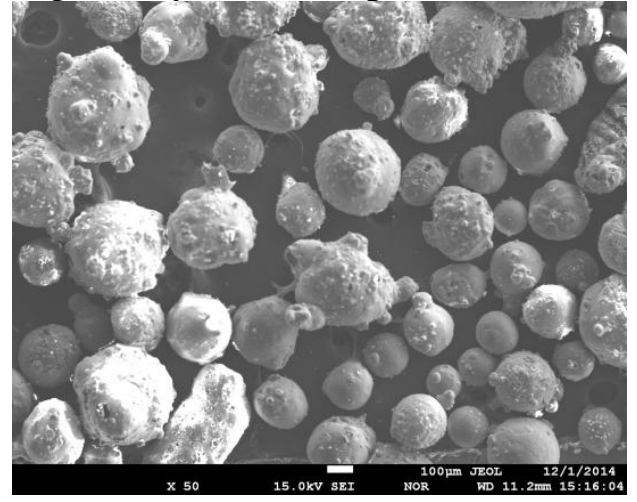

(a) non-ball milled FAC

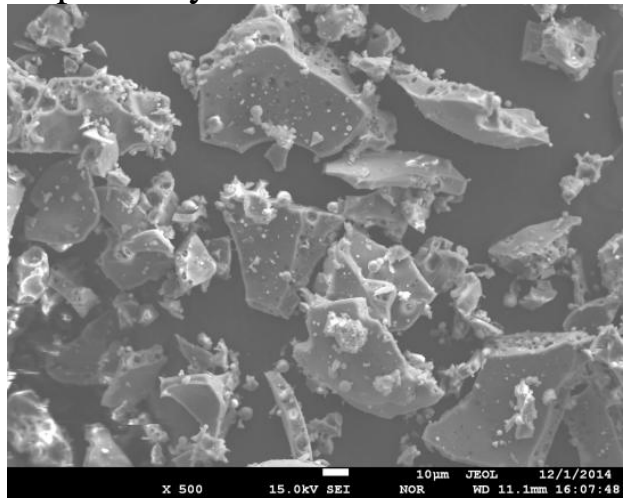

(b)ball milled FAC

Fig. 1 The morphology of FAC

\subsection{Analysis of microstructure and damping capacities}

The phases of magnesium matrix composites were identified using X-ray diffraction (XRD, D/MAX2000PC, CuK $\alpha$, Japan). The microstructures of four kinds of Mg matrix composites were carried out using optical microscope(OM).

The damping capacities of the four composite specimens were measured using Dynamic MechanicalThermal Analyzer (DMTA-Q800, TA Instruments).The damping capacity was determined by Q-1=tan $\varphi$, where $\varphi$ was the lag angle between the applied strain and the response stress. The measurement conditions included the constant frequency(f) of $0.5,1.0$, and $5.0 \mathrm{~Hz}$, respectively, the maximum strain amplitude $(\varepsilon)$ of $1 \times 10-3$, the temperature range from $20(C$ to $300(\mathrm{C}$, and the constant heating rate was $5(\mathrm{C} / \mathrm{min}$. The size of rectangular double antilever bending beam specimens for damping capacities measurements was $60 \mathrm{~mm} \times 6 \mathrm{~mm} \times 1 \mathrm{~mm}$.

\section{Result and discussion}

\subsection{Phases analysis}

The XRD patterns of AZ91D alloy and FAC /AZ91D composites were showed in Fig.2.

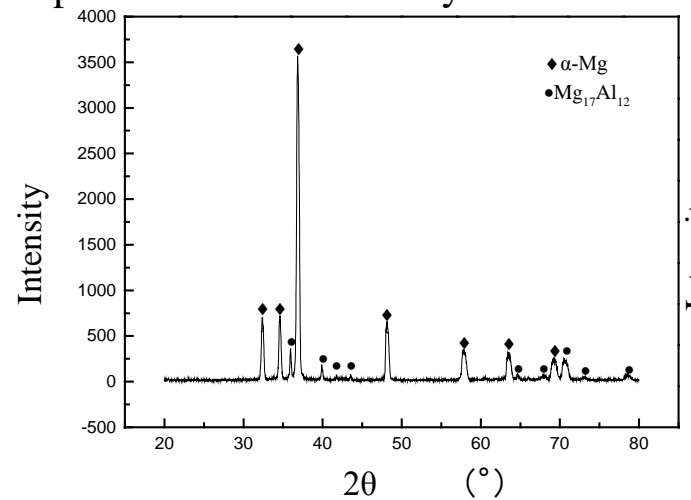

(a) AZ91D alloy

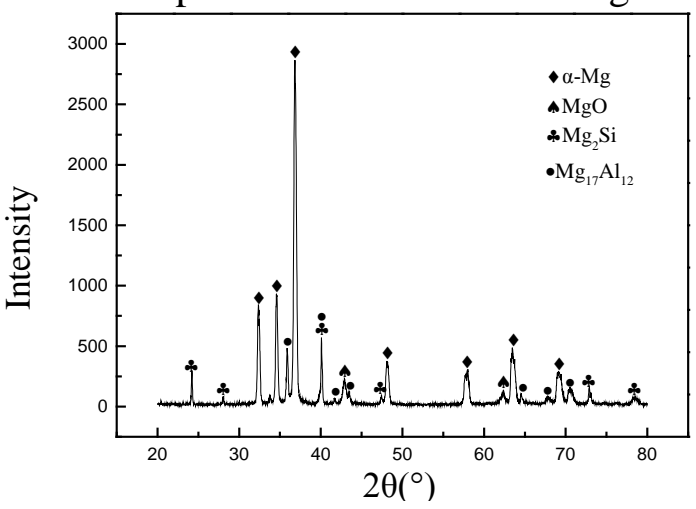

(b) FAC/AZ91D composites

Fig.2 XRD patterns of AZ91D and FAC/AZ91D composites

From Fig.2 (a), Magnesium alloy mainly composed of $\alpha$-Mg and $\beta$-Mg17Al12. After adding FAC, there are two new phases of MgO and Mg2Si(see Fig.2(b)). The reason is the reaction between $\mathrm{SiO} 2$ in FAC and Mg alloy.

\subsection{Microstructure}

The microstructures of four kinds of FAC/AZ91D composites are shown in Fig.3. Both S1(see Fig.3(a)) and S2 (see Fig.3(b)) have many Mg2Si phases, and there are a large of full FACs in S2, while more even particle size in S3 (see Fig.3(c)) than that of S1. Comparing S2 and S4, the smaller particle size, the more broken FAC (see Fig.3(d)), possibly because of the high-speed rotation of the impeller or the reaction between some FAC and magnesium alloy matrix[6]. 


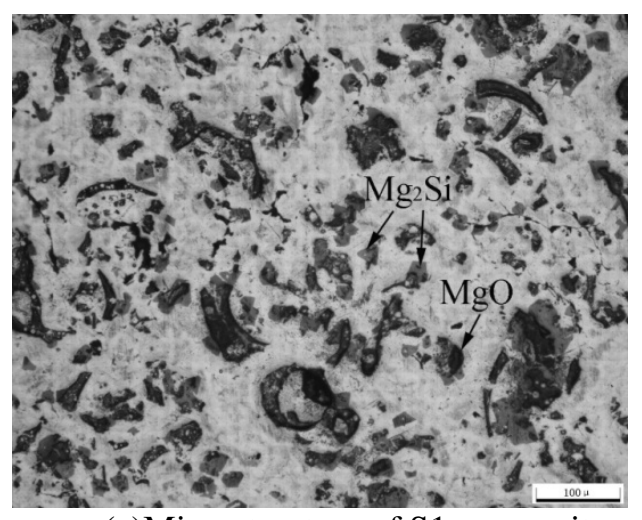

(a)Microstructure of S1 composite

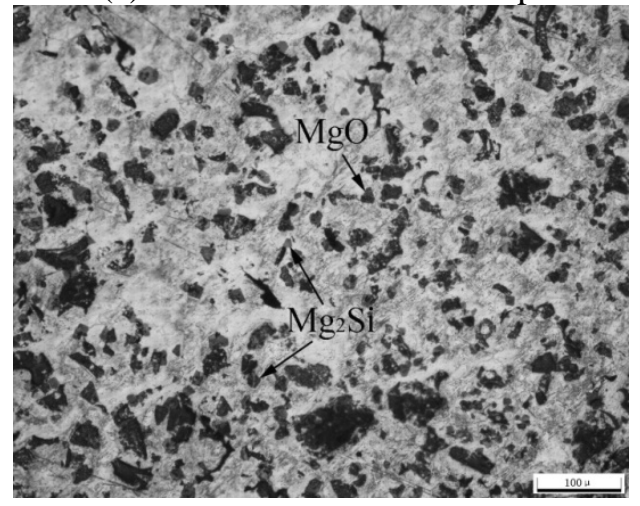

(c) Microstructure of S3 composite

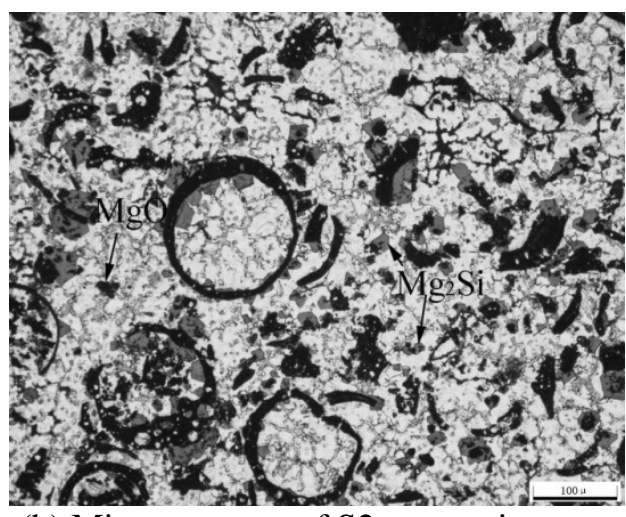

(b) Microstructure of S2 composite

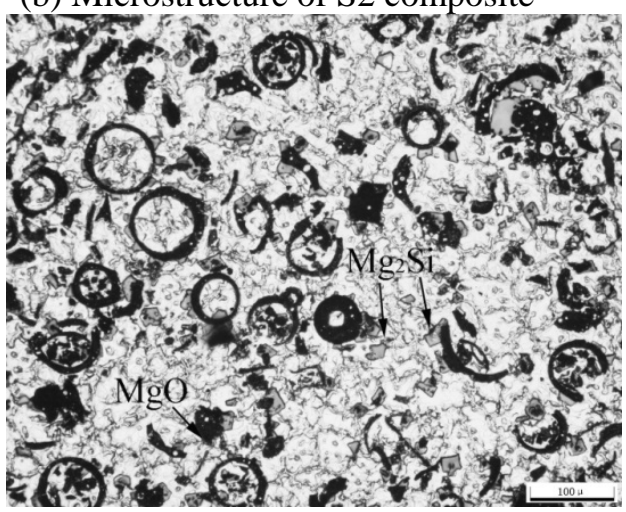

(d) Microstructure of S4 composite

Fig.3 The microstructure of four kinds of Mg matrix composites

\subsection{Damping capacities of four kinds of FAC/AZ91D composites}

\subsubsection{Damping capacities at room temperature}

Fig.4 shows the curves of the damping capacities $\mathrm{Q}^{-1}$ versus the strain amplitude at room temperature for the four kinds of Mg matrix composites S1, S2, S3 and S4.

The damping capacity of the S1 was higher than that of the S2, which showed that the ball-mill technique was effectively to increase the damping capacity of Mg matrix composites. According to analyze the damping value at room temperature, the ratio of ball-mill technique factor and average particles size was about 1.15 .

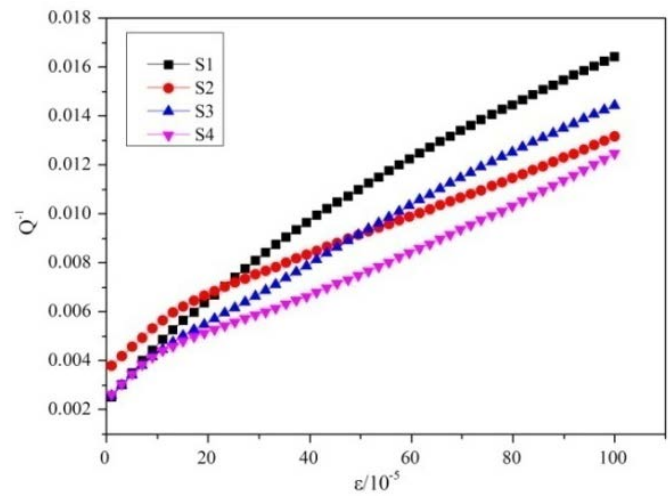

Fig.4 Damping capacities to strain amplitude

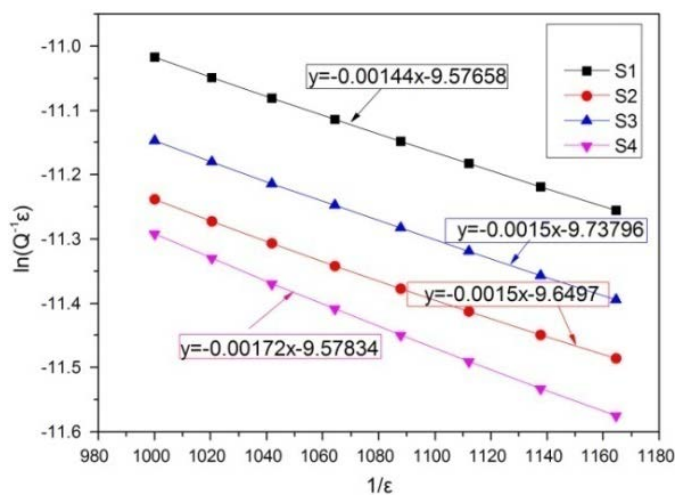

Fig.5 G-L plots of FAC/AZ91D

From the Granato-Lüecke (G-L) theory[7], the dislocation damping plays a decisive role in the correlation of the material damping capacity and the strain amplitude, it must be linear relationship between $\ln \left(\mathrm{Q}^{-1} \varepsilon\right)$ and $1 / \varepsilon[8]$ (see Fig.5).

\subsubsection{Damping capacities at elevated temperature}

Fig. 6 shows the curves of the damping capacities $\mathrm{Q}^{-1}$ versus the temperature for $\mathrm{S} 1$ and $\mathrm{S} 2$, S3 and S4 Mg matrix composites.

The damping capacity of the S1 at elevated temperature was higher than that of the S2, which shows that at elevated temperature the ball-mill technique was effectively to increase the damping capacity. The grain boundary contributes to the damping peak at about $125^{\circ} \mathrm{C}[9]$. With the increase 
of the temperature, much energy dissipates between the movable interfaces of the composites, so the damping property is rapidly improved. The damping peak at about $225^{\circ} \mathrm{C}$ is contributed to the movable interfaces between magnesium alloy and FAC.

Moreover, Fig.6 shows that the damping capacity of S3 was higher than that of S1 at elevated temperature. Ball-mill technique has remained a greater effect on the damping capacity than the average size. According to analyze the damping valueat elevated temperature, the ratio of ball-mill technique factor and average particles size was about 1.08 .

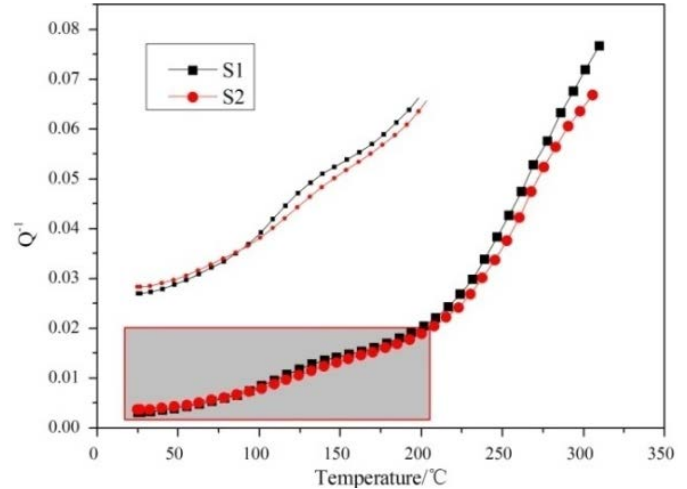

(a) Damping capacities of S1and S2composites

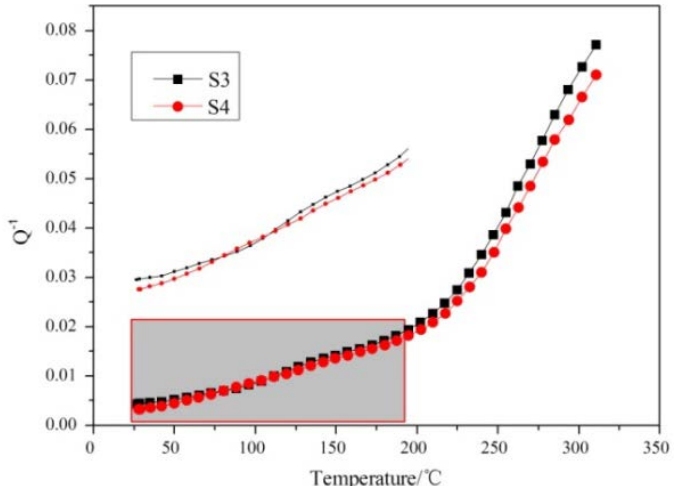

(b) Damping capacities of S3and S4 composites

Fig.6 Damping capacities of FAC/AZ91D composites corresponding to temperature

\section{Conclusions}

(1) Compared to AZ91D Mg alloy containing $\alpha-\mathrm{Mg}$ and $\beta-\mathrm{Mg}_{17} \mathrm{Al}_{12}$, all of the four kinds of $\mathrm{Mg}$ matrix composites contain $\mathrm{Mg}_{2} \mathrm{Si}$ and $\mathrm{MgO}$ phases.

(2) Ball-milled technique has more effective on the damping capacity, the particles morphology has a greater $15 \%$ impact on damping capacities than the particles size at room temperature, and $8 \%$ at elevated temperature.

\section{Acknowledgements}

This work was supported by the Key Grant Project of Chinese Ministry of China Education (No:313056) and Fundamental Research Funds for the China Central Universities(14CX02132A).

\section{References}

[1] X.Q. Zhang, L.H.Liao, N.H. Ma: Compos. Part A-Appl. S. Vol.37(2006), p.2011

[2] G.H. Wu, Z.Y. Dou, L.T Jiang: Mater. Lett. Vol.60 (2006), p.2945

[3] Z.Q. Huang, S.R Yu: J. Alloy Compd. Vol.509 (2011), p.311

[4] Z.Q. Huang, S.R Yu: T. Nonferr. Metal Soc, Vol.20 (2010),p 458

[5] I.A. Ibrahim, F.A. Mohamed, E.J. Lavernia: Mater. Sci. Vol. 26 (1991), p 1137

[6] L.H. Liao, H.W. Wang, X.F. Li, et al. Mater. Lett. Vol. 61(2007), p2518

[7] A. Granato, K. Lucke: J. Appl. Phys Vol.27 (1956),p583

[8] J. Zhang, R.J. Perez, C.R. Wong: Mater. Sci. Eng. R, Vol.13 (1994),p325

[9] P. Poddar, V.C. Srivastava, P.K. De: Mat. Sci. Eng. A-Struct Vol.460 (2007)p357 